ОБЩАЯ ПСИХОЛОГИЯ, ПСИХОЛОГИЯ ЛИЧНОСТИ, ИСТОРИЯ ПСИХОЛОГИИ GENERAL PSYCHOLOGY, PSYCHOLOGY OF PERSONALITY, HISTORY OF PSYCHOLOGY

УДК 159.9.07

\title{
СИСТЕМНО-СТРУКТУРНЫЙ АНАЛИЗ ТЕОРИЙ ПСИХОЛОГИЧЕСКИХ ТРАНСФОРМАЦИЙ ЛИЧНОСТИ
}

Ирина В. Абакумова ${ }^{1}$, Евгения Н. Рядинская ${ }^{1}$, Вера М. Голубова

${ }^{1}$ Южный федеральный университет, г. Ростов-на-Дону,

Российская Федерация

${ }^{2}$ Ставропольский институт кооперации (филиал) Белгородского университета кооперации, экономики и права, г. Ставрополь,

Российская Федерация

*E-mail: ivabakumova@sfedu.ru

Исследование выполнено при поддержке гранта (задание Минобрнауки № 8.4334.2017/HM)

В данной статье представлен системно-структурный анализ теорий психологических трансформачий личности, раскрывающий основные методологические подходы к определению сущности изменений личности. Особое внимание уделено трансформациям ценностно-смысловой сферы личности.

В статье дано определение понятия «трансформация» с разных сторон психологической науки. Представлен обзор теорий и подходов разных авторов к изучению личности и ее трансформачии. Выделены динамические, статические теории личности, а также теории развития и трансформации. Дана подробная характеристика психотрансформационного подхода с выделением искусственных и естественных трансформаций.

В статье рассмотрены различные модели и формы трансформации личности. Подробно представлены: «теория поля», основанная на понятиях «анализа тенденций» или «сил», создающих барьеры или помогающих преобразованиям, и «теория кристаллизации недовольства», способствующая образованию ассоциативных связей между субъективным восприятием проблем, затрат и негативных результатов.

Авторы классифицируют рассмотренные подходы по нескольким параметрам: закономерностям развития, влиянию ситуации и контекста деятельности, характеру когнитивной активности, специфике механизмов сопротивления любым изменениям. 
Анализ рассмотренных подходов и моделей показывает, что возможности преобразований личности исходят из уровня, на котором изучается сама личность. Взгляд на изменения личности с точки зрения уровней функционирования подчеркивает особенности прочессов трансформачии, характерных для каждого из них, и предполагает, что быстрый темп преобразований личности является характерным признаком смыслового уровня.

На основе проведенного системно-структурного анализа теорий психологических трансформаций личности авторы предлагают дифференцировать возможные изменения личности на уровне личностной активности человека, черт его индивидуальности, и на смысловом уровне. Авторы делают вывод о том, что важным является изучение трансформаций личности, находящейся в зоне вооруженного конфликта с точки зрения когнитивных, афрективных и поведенческих проявлений.

Ключевые слова: трансформачия, трансформачионные прочессы, теории личности, модели трансформаций, уровни трансформаций, смысл, ченностно-смысловая сфера, вооруженный конфликт, постконфликтный период, постконфликтное восстановление.

Для цитирования: Абакумова И. В., Рядинская Е. Н., Голубова В. М. Системноструктурный анализ теорий психологических трансформаций личности // Российский психологический журнал. - 2017. - Т. 14.- № 1. - С. 10-24.

UDC 159.9.07

doi: 10.21702/rpj.2017.1.1

\section{SYSTEMIC AND STRUCTURAL ANALYSIS OF THEORIES OF PSYCHOLOGICAL TRANSFORMATIONS OF PERSONALITY}

Irina V. Abakumova ${ }^{1 *}$, Evgeniya N. Ryadinskaya ${ }^{1}$, Vera M. Golubova ${ }^{2}$

${ }^{1}$ Southern Federal University, Rostov-on-Don, Russian Federation

2 Stavropol Branch, Belgorod University of Cooperation, Economics and Law,

Stavropol, Russian Federation

* Correspondence author. E-mail: ivabakumova@sfedu.ru

\section{Acknowledgments}

The study was supported by a grant from the Ministry of Education (project no. 8.4334.2017)

The paper presents a systematic and structural analysis of the theories of psychological transformations of personality revealing the main methodological 
approaches to studying personality changes. Transformations of the person's sensevalue sphere are of special interest.

The study (a) analyses the psychological definitions of the "transformation" concept; (b) provides an overview of various theories and approaches to studying personality and its transformations; (c) reveals dynamic and static theories of personality, as well as theories of development and transformation; (d) describes in detail a psychotransformational approach; (e) highlights artificial and natural transformations.

The paper considers various models and forms of personal transformation and also presents a "field theory", which is based on the concepts of "analyzing tendencies" or "forces" creating barriers or promoting transformations, and a "theory of dissatisfaction crystallization", which forms associative relations between subjective perception of problems, expenditure, and negative results.

The considered approaches are classified according the following parameters: principles of development, influence of a situation and the context of activity, types of cognitive activity, and mechanisms of resistance to any changes.

The analysis of the considered approaches and models shows that the level of studying personality determines potentialities of its transformation. Personality changes from the standpoint of functioning levels determine the transformation processes specific to each of them. Fast-paced transformations of personality are characteristic for the sense level.

The systemic and structural analysis of the theories of psychological transformations of personality suggests differentiating possible personality changes at the level of personal activity, personal traits, and at the sense level. Future work will involve studying cognitive, affective, and behavioral transformations of a person in the zone of armed conflict.

Keywords: transformation, transformation processes, personality theory, transformation models, transformation levels, sense, sense-value sphere, armed conflict, post-conflict period, post-conflict reconstruction.

For citation: Abakumova I. V., Ryadinskaya E. N., Golubova V. M. Systemic and structural analysis of theories of psychological transformations of personality. Rossiiskii psikhologicheskii zhurnal - Russian Psychological Journal, 2017, V. 14, no. 1, pp. 10-24 (in Russian).

Original manuscript received 22.10.2016

\section{Введение}

На современном этапе развития общества проблема психологических последствий экстремальных ситуаций, межгосударственных, межнациональных, межэтнических конфликтов и локальных войн вызывает серьезную озабоченность. Это обусловлено тем, что ежегодно в мире происходят 
десятки социально-политических конфликтов внутри страны или за рубежом, от которых страдают десятки тысяч людей. Мирные жители, проживающие на территориях вооруженных конфликтов, так или иначе психологически вовлечены в экстремальные ситуации, связанные с ними, и определенным образом реагируют на них. Становится очевидным, что человек, длительное время находящийся в зоне вооруженного конфликта, уже не останется прежним, с ним происходят определенные личностные изменения.

Вслед за острой фазой вооруженного конфликта наступает постконфликтный период, который характеризуется переосмыслением личных и общественных интересов, оценкой политического, экономического, социального ущерба, а также психологического ущерба. Именно в этот период начинается постконфликтное восстановление - проект обеспечения устойчивого развития, рассчитанный на длительный срок, который основывается на поддержании мира и относительной стабильности посредством программ, реализуемых в течение несколько лет, учитывая специфику региона [50].

Необходимо отметить, что в этот период разработка программ психологической помощи людям, проживающим в зоне вооруженного конфликта, должна быть направлена на преодоление негативных последствий для сохранения психического и соматического здоровья человека. Таким образом, психологические проблемы личности и ее трансформации в современном мире приобретают все большую актуальность. Рассматривая и систематизируя теории психологических трансформаций личности, можно определить теоретико-методологические предпосылки исследований.

Целью данной статьи является проведение структурно-системного анализа существующих теорий психологических трансформаций личности.

\section{Анализ основных исследований и публикаций}

На протяжении столетий феномен личности исследовался как зарубежными (А. Бандура [5], Д. Зиглер [39], Дж. Келли [48], С. Мадди [25], А. Маслоу [49], Г. Олпорт [27], Б. Скиннер [33], В. Франкл [35, 46], К. Хорни [38], Л. Хьелл [39]), так и отечественными исследователями (Б. Г. Ананьев [4], В. М. Бехтерев [7], Л. С. Выготский [10], А. Ф. Лазурский [17], А. Н. Леонтьев [20], Б. Ф. Ломов [23], М. Ш. Магомед-Эминов [24], В. С. Мерлин [26], С. Я. Рубинштейн [31] и др.).

В то же время в научной психологической литературе представлено большое разнообразие теорий и подходов к личности и ее трансформации. Выделяют динамические (А. Адлер [3], 3. Фрейд [36], К. Юнг [40, 41]) и статические (Р. Б. Кеттелл [44], Э. Кречмер [16], А. Е. Личко [22], У. Шелдон [51] и др.) теории личности, теории развития (А. Маслоу [49], К. Роджерс [30]) и трансформации личности (Ю. Б. Гиппенрейтер [11], В. В. Козлов [14], В. А. Кольцова [9] и др.). 


\section{Изложение основного материала исследования}

Смысл динамической теории личности заключается в анализе адаптивных свойств индивида к жизни в обществе, а всякое поведение выступает как адаптация [28]. Динамический взгляд на личность демонстрирует большое влияние на нее событий, которые происходят на протяжении всей жизни, тем самым изменяя ее. Таким образом, постоянная конфликтность сознательного и бессознательного в личности предопределяет динамический тип реагирования.

Представители статической теории личности указывают на некое генетически детерминированное «ядро» личности. И не важно, какие типические черты чаще всего проявляются у человека, принципиально нового в его характеристиках не наблюдается [25].

А. Маслоу, предлагая теорию развития личности, считает, что личность, чтобы быть современной и востребованной, должна постоянно совершенствоваться и самоактуализироваться [49].

Рассматривая теории трансформации личности, необходимо определить понятие «трансформация». Термин «трансформация» происходит от латинских слов «trans» и «forma». Слово «trans» имеет несколько значений: «через», «пере-» (перехожу), «сквозь» (пронзаю насквозь), «за» (за пределами), и «forma» - превращать, преобразовать [34]. В психотерапии понятие «трансформация» используется для описания психологического перехода, который включает в себя регрессию и временную утрату эго, к сознанию и реализации ранее не осознанной психологической потребности.

Одним из первых научную психологическую теорию о трансформации личности создал А. Ф. Лазурский, который считал основной задачей личности приспособление к окружающей среде [17].

Позднее К. Юнг, характеризуя трансформации личности, вводит понятие «индивидуация». Индивидуация - это естественный процесс раскрытия внутренней природы, главной цели и жизненного пути человека, включающих в себя постижения целостности, становление и развитие динамической связи между эго и самостью, благодаря чему происходит интеграция различных частей психики и других архетипов бессознательного [41].

В современной психологии заслуживает внимания психотрансформационный подход М. Ш. Магомед-Эминова [24], который, обобщив существующие теории трансформации, в самом общем виде определяет ее как порождающий процесс, в ходе которого осуществляется психическая работа личности по преобразованию исходного содержания в трансформированную предметность. По мнению автора, существует два вида трансформации личности: экзотрансформация, отражающая содержание психики из глубины, а затем, переработав и обогатив ее новым содержанием 
реальности, погружающая в ее глубины, и эндотрансформация - преобразование личности из одной целостности в другую, но с большей полнотой, зрелостью и самореализацией.

М. Ш. Магомед-Эминов дает наиболее детальную систематизацию трансформационных процессов, происходящих с человеком. Автор разделил их на естественные и искусственные. К «естественным» он отнес те изменения, которые происходят с человеком в онтогенезе и не связаны с использованием специальных средств внедрения в психику человека (например, жизненные кризисы). Искусственными трансформациями автор назвал изменения, которые происходят под влиянием организованного воздействия (например, психофизиологический опыт).

Автор подробно классифицирует трансформации личности, выделяя следующие ее формы: базисная, индукционная, возрождающая, индивидуационная, конструктивная, нормативная, потенциирующая, самореализующая, которые он относит к «естественным», и трансцендентная, травмотрансформация, экзистенциальная, относящиеся к «искусственным» [24]. В контексте исследования трансформаций личности, находящейся в зоне вооруженного конфликта и в постконфликтный период, нам интересны именно искусственные трансформации.

Рассмотрим некоторые формы трансформаций, связанные с воздействием на личность, предлагаемые М. Ш. Магомед-Эминовым.

Базисная трансформация, по мнению автора, опирается на идеи производного содержания и понятия о базисно-надстроечном строении личности. Результатом порождающей трансформации является ее производное содержание. В процессе психического действия трансформации психическое содержание личности подвергается преобразованиям, следствием чего является производное содержание - трансформер. Таким образом, все, что происходит с личностью, является выражением ее прошлой душевной жизни.

Автор рассматривает индукционную трансформацию как участие человека в массовых ритуалах. К. Юнг также описал подобную трансформацию личности в виде переживания ею трансцендентности жизни. Будучи участником массовых мероприятий, человек трансформируется посредством выполнения определенных ритуальных действий [41].

Актуализацию мотивации, направленной на рост и самоактуализацию личности, представляет собой потенциирующая трансформация [34].

Возрождающая трансформация дает человеку шанс изменить свою жизнь, выйдя за рамки привычного, стереотипного существования. Какой бы ни была жизнь человека счастливой и стабильной, если его личность не будет обновляться и развиваться, она потеряет смысл и приведет к «застою». Важным видом возрождающей трансформации является трансформация личности 
в ситуации экстремального существования, жизни в условиях опасности и угрозы. Таким образом, можно заключить, что жизнедеятельность человека в ситуации угрозы потери жизни не только травмотрансформационна, но и вызывает возрождающие трансформации. Осознав возможность потерять жизнь, человек может не только психологически «умереть», но, напротив, найти в себе силы для изменений [24].

Модели трансформации личности рассматриваются также и другими авторами. Ряд авторов $[6,15,24]$ выделяют потенциирующую трансформацию, в ходе которой актуализируется соответствующая мотивация и в определенных формах реализуется личностный рост человека, происходит самоактуализация.

Э. Эриксон называл нормативной трансформацией последовательное развитие индивида по отчетливому психосоциальному алгоритму или по сменяющимся трансформационным этапам. Автор описал одну из модификаций такой трансформации в своей эпигенетической теории развития личности [34].

Наряду с естественными трансформациями, рассмотренными выше, существуют и искусственные - психические превращения, преобразования личности в целом или отдельных ее составляющих, возникающие под влиянием специально организованного воздействия. Основными целями искусственной трансформации личности могут быть: 1) сужение личности, т. е. устранение какого-то симптома, комплекса, болезни; 2) расширение личности - обретение новых качеств, ценностей, навыков и др.; 3) развитие потенции, способность видеть возможности вокруг себя; 4) преодоление задержки, ингибиторного процесса; 5) становление бытия. Рассмотрим их подробнее.

Трансцендентная трансформация характеризуется концепциями К. Юнга, А. Маслоу, Р. Ассаджиоли, С. Грофа, которые считали, что такая трансформация смещает акцент на реализацию высших ценностей бытия (в пиковых переживаниях, плато-состояниях) и учитывает пренатальный и трансцендентальный опыт [12].

Травмотрансформация определяется особенностями способа существования личности, требующего от человека задействования глубинных потенциалов личности, включения особого - экстремального режима функционирования [24].

Трансформацию способов существования называют экзистенциальной трансформацией. Она может быть аутентичной и неаутентичной (Л. Бинсвангер, М. Босс и др.) [37].

Достаточно подробной представляется модель К. Левина «Теория поля». Она основана на понятиях «анализа тенденций» или «сил», создающих барьеры или помогающих преобразованиям. Он подчеркивает, что индивидуальное 
и групповое поведение происходят в специфическом психологическом поле, которое характеризуется наличием сил, что и способствует или препятствует достижению поставленной человеком цели [19].

Интересной, на наш взгляд, является теория «кристаллизации недовольства» Р. Баумайстера, в которой причинами изменений выступает субъективная оценка человеком событий, которые происходят в его жизни [43].

Концепция «кристаллизация недовольства» способствует образованию ассоциативных связей между субъективным восприятием проблем, затрат и негативных результатов. Вместо обрывочной картины личных проблем человек истолковывает их как комплексную и неизбежную последовательность, именно поэтому «кристаллизация недовольства» мотивирует преобразования и является решающим фактором их появления. Следовательно, процессы субъективной интерпретации коренным образом изменяются, поддерживая склонность к применению существующих образцов поведения или стабилизируя сформировавшиеся качества личности.

Анализ вышерассмотренных концепций объясняет сохранение стабильности личности и сопротивление преобразованиям, а также механизмы происходящих трансформаций, процессы которых проходят достаточно длительное время. Однако иногда такие изменения могут происходить резко и неожиданно, т. е. включается критерий «стремительности», что требует соответствующего объяснения. Примером может служить модель «суммарных изменений» W. Miller и J. C'Debaca, которая объясняет причину, почему мысли, чувства, ценности, понимание ситуации резко изменяются на новые [47].

Заслуживает внимания и уровневая модель трансформации личности T. Heatherton. Автор выделяет определенные уровни, на которых могут рассматриваться преобразования индивида: уровень черт личности (диспозициональный), уровень «личностной активности» (включаются адаптивные, защитные, мотивационные и иные стратегии, которые человек использует для достижения жизненно важных целей), смысловой уровень (программа личностной идентичности, объединение разрозненных диспозиций и стратегий) [47].

Интересен для исследования и смысловой уровень трансформации личности. Категории смысла в разное время рассматривали как отечественные, так и зарубежные авторы (И. В. Абакумова [42], К. А. АбульхановаСлавская [2], Б. Г. Братусь [8], П. Н. Ермаков [1], Л. Ю. Крутелева [13], К. Левин [18], Д. А. Леонтьев [21], А. В. Серый [32], В. Франкл [35, 46] и пр.). В научной психологической литературе анализируются два подхода к пониманию смысла: смысл как единица сознания и деятельности личности и смысложизненная проблема.

Нередко смысл рассматривается как системное качество личности, которое обусловливает эмоциональные, когнитивные и поведенческие компоненты психики, порождая различные составляющие ее активности. В условиях 
постоянно возрастающих и изменяющихся требований окружающей среды, восприятие человека как целостного, уникального индивидуума напрямую связано со смысловой природой, где основной функцией смысла является регуляция жизнедеятельности.

Дж. Дьюи писал, что преднамеренный интенциальный контроль над вещами возникает только тогда, когда они приобретают для человека определенный смысл, и он может понять последствия их реализации. В этом понимании преобразования индивида на уровне смыслов являются непрерывным, постоянным процессом [45].

Трансформации по форме социальной организации делятся на социализирующую и интерактивную. Социализирующая трансформация характеризуется последовательным движением личности в процессе ее социализации, интерактивная - приобщением личности к субкультуре какого-либо сообщества, где изменения вызваны участием в ритуалах и пр. [29].

\section{Выводы}

Таким образом, анализируя вышеизложенное, можно заключить, что в процессе жизни и развития личность подвержена различным трансформационным изменениям, уровень которых неоднозначен. Рассмотрены и описаны различные подходы к трансформации личности, выделены виды и формы, а также они структурированы по нескольким параметрам: закономерностям развития, влиянию условий и контекста деятельности, познавательной активности, особенностям механизмов сопротивления любым изменениям.

Анализ рассмотренных моделей, показывает, что возможности преобразований личности исходят из уровня, на котором изучается сама личность. Взгляд на изменения личности с точки зрения уровней функционирования подчеркивает особенности процессов трансформации, характерных для каждого из них, и предполагает, что быстрый темп преобразований личности является характерным признаком смыслового уровня. По нашему мнению, в контексте исследования трансформаций личности в вооруженном конфликте и в постконфликтный период представляет интерес критерий «стремительности» происходящих преобразований, который позволяет сделать акцент на изменениях в когнитивной, аффективной и поведенческой сферах личности $[42,50]$.

\section{Литература}

1. Абакумова И. В., Кагермазова Л. Ц., Ермаков П. Н. Технологии направленной трансляции смыслов в практике учебного процесса: монография. - М.: КРЕДО, 2016. - 234 с.

2. Абульханова К. А., Березина Т. Н. Время личности и время жизни. - СПб.: Алетейя, 2001. - 304 с. 
3. Адлер А. Практика и теория индивидуальной психологии: пер. с нем., вступ. ст. А. М. Боковикова. - М., 1995. - 326 с.

4. Ананьев Б. Г. О проблемах современного человекознания. - СПб.: Питер, 2001. - 275 c.

5. Бандура А. Теория социального научения. - СПб.: Евразия, 2000. С. 13-28.

6. Бернштейн С. Б. Зигзаги памяти. Воспоминания. Дневниковые записи / Отв. ред. ак. РАН В. Н. Топоров. - М., 2002. - 394 с.

7. Бехтерев В. М. Избранные труды по психологии личности: В 2 т. / Отв. ред. Г. С. Никифоров, Л. А. Коростылева. - СПб.: Алетейя, 1999. - Т. 1: Психика и жизнь. - 256 с.

8. Братусь Б. С. К изучению смысловой сферы личности // Вестник Московского ун-та. Сер. 14. Психология. - 1981. - № 2. - С. 46-56.

9. Брушлинский А. В., Кольцова В. А. Социально-психологическая концепция В. М. Бехтерева // Избранные работы по социальной психологии. М.: Наука, 1996. - С. 145-149.

10. Выготский Л. С. Собрание сочинений. - М., 1983. - Т. 3. - 641 с.

11. Гиппенрейтер Ю. Б. Психология эмоций: тексты / Под ред В. К. Вилюнаса. - М., 1984. - 336 с.

12. Гроф К. Духовный кризис: Когда преобразование личности становится кризисом. - М., 2003. - 377 с.

13. Кара Ж. Ю., Крутелева Л. Ю. О соотношении понятий: смысложизненные ориентации, смысложизненные стратегии и смысложизненная концепция личности // Известия Южного федерального университета. Педагогические науки. - 2012. - Т. 1. - С. 111-116.

14. Козлов В. В., Козлова А. А. Управление конфликтом. - М.: ЭКСМО, 2014. $224 \mathrm{C.}$

15. Коллинз P. Социология философий. Глобальная теория интеллектуального изменения. - Новосибирск: Сибирский хронограф, 2002. - 1282 с.

16. Кречмер Э. Медицинская психология: пер. с англ. - М.: Союз, 1989. - 464 с.

17. Лазурский А. Ф. Классификация личностей. 3-е изд. - Л.: Госиздат, 1924. - 290 с.

18. Левин К. Динамическая психология: Избранные труды. - М.: Смысл, 2001. - 572 c.

19. Левин К. Теория поля в социальных науках: пер. с англ. - СПб.: Сенсор, 2000. - 368 c.

20. Леонтьев А. Н. Деятельность. Сознание. Личность. - М.: Политиздат, 1975. - $170 \mathrm{c}$.

21. Леонтьев Д. А. Теория личности А. Ф. Лазурского: от наклонностей к отношениям // Методология и история психологии. - 2008. - Т. 3. Вып. 4. - С. 7-20. 
22. Личко А. Е. Психопатии и акцентуация характера у подростков. Изд. 2-е доп. и перераб. - Л.: Медицина, 1983. - 256 с.

23. Ломов Б. Ф. Методологические и теоретические проблемы психологии. - М.: Наука, 1984. - 445 с.

24. Магомед-Эминов М. Ш. Деятельностно-смысловой подход к психологической трансформации личности. Кн. 1-2: дисс. ... д. психол. наук. M., 2009. - 680 c.

25. Мадди С. Теории личности: сравнительный анализ: пер. с англ. - СПб.: Речь, 2002. - 539 с.

26. Мерлин В. С. Психология индивидуальности. - Воронеж: МОДЭК; Москва: Изд-во Института практической психологии, 1996. - 448 с.

27. Олпорт Г. Становление личности: Избранные труды: пер. с англ. Л. В. Трубицыной и Д. А. Леонтьева / Под общ. ред. Д. А. Леонтьева. - М.: Смысл, 2002. - $356 \mathrm{c}$.

28. Пиаже Ж. Психология интеллекта / Пер. А. М. Пятигорского. - СПб., 2003. - C. 3.

29. Римарева И. И. Трансформация личности ученого (автобиографический экскурс) // Молодой ученый. - 2014. - № 8. - С. 725-730.

30. Роджерс К. Р. Клиент-центрированная психотерапия: пер. с англ. М.: ЭКСМО-Пресс, 2002. - 175 с.

31. Рубинштейн С. Л. Избранные философско-психологические труды. Основы онтологии, логики и психологии. - М.: Наука, 1997. - 463 с.

32. Серый А. В. Психологические механизмы функционирования системы личностных смыслов. - Кемерово: Кузбассвузиздат, 2002. - 183 с.

33. Скиннер Б. Оперантное поведение // История зарубежной психологии (30-60-е гг. XX в.). Тексты. - М., 1986.

34. Урываев В. А., Бойчук Б. В. Трансформации личности как многоаспектная проблема // Клиническая и медицинская психология: исследования, обучение, практика. - 2013. - № 2 (2). - URL: http://medpsy.ru/climp

35. Франкл В. Человек в поисках смысла: биографический очерк. - М.: Прогресс, 2010. - 368 с.

36. Фрейд 3. Очерки по истории психоанализа // «Я» и «ОНО». - Тбилиси, 1991. - Т. 1. - 274 с.

37. Холл К., Линдсей Г. Теории личности. - М.: КСП+, 1997. - 720 с.

38. Хорни К. Собрание сочинений: В 3 т.: пер. с англ. - М.: Смысл, 1997. - 342 с.

39. Хьелл Л., Зиглер Д. Теории личности. - СПб.: Питер Пресс, 1997. - 275 с.

40. Юнг К. Г. Психологические типы. - СПб.: Ювента, 1995. - 717 с.

41. Юнг К. Г. Символы трансформации. - M.: Penta-Graphic, 2000. - 496 с.

42. Abakumova I., Kruteleva L., Ryadinskaya E. Transformation of Life-Sense Strategies of a Person in the Armed Conflict Environment: Theoretical 
Research // 6th.World Congress of Psychology and Behavioral Sciences (Management, Psychology, Political and Social Sciences) (WCPBS2016). Barselona, 2016. - pp. 1-6.

43. Baumeister R., Leary M. The Need to Belong: Desire for Interpersonal Attachments as a Fundamental Human Motivation // Psychological Bulletin. 1995. - no. 117. - pp. 113-115.

44. Cattell R. B. The birth of the Society of Multivariate Experimental Psychology // Journal of the History of the Behavioral Sciences. - 1990. - 26 (1). pp. 48-57.

45. Dewey J. The quest for certainty. - N. Y., Minton: Balch, 1929. - 283 p.

46. Frankl V. E. The unheard cry for meaning: Psychotherapy and humanism. New York, NY: Simon \& Schuster, 2011. - 184 p.

47. Heatherton T. F., Weinberger J. L. Can personality change? - Washington (DC): American Psychological Association, 1994. - 301 p.

48. Kelly G. A theory of personality: The psychology of personal constructs. New York: Norton, 1963. - pp. 238-240.

49. Maslow Abraham H. Towards a Psychology of Being. Third edition. - NY: John Wiley \& Sons, 1998. - p. 89.

50. Ryadinskaya Yev. Theoretical analysis of a systematic approach to the study of the strategies of life meaning of the individual under an armed conflict //"The Tenth International Conference on Eurasian scientific development". Proceedings of the Conference (September 02, 2016). - Vienna, 2016. - pp. 40-43.

51. Sheldon B. Behavioral Approaches with Psychiatric Patients // Social Work and Mental Health. - L.: Tavistock Publications, 1984. - pp. 243-324.

\section{References}

1. Abakumova I. V., Kagermazova L. Ts., Ermakov P. N. Tekhnologii napravlennoi translyatsii smyslov $v$ praktike uchebnogo protsessa [Techniques of the directed transmission of senses in the educational process]. Moscow, KREDO Publ., 2016. 234 p.

2. Abul'khanova K. A., Berezina T. N. Vremya lichnosti i vremya zhizni [Time of personality and time of life]. St. Petersburg, Aleteiya Publ., 2001. 304 p.

3. Adler A. The practice and theory of individual psychology. New York: Harcourt, Brace \& Jovanovich, 1924. (Russ. ed.: Adler A. Praktika i teoriya individual'noi psikhologii. Moscow, 1995. 326 p.).

4. Anan'ev B. G. O problemakh sovremennogo chelovekoznaniya [On the problems of modern human study]. St. Petersburg, Piter Publ., 2001. 275 p.

5. Bandura A. Social learning theory. Englewood Cliffs. NJ: Prentice-Hall, 1977. 247 p. (Russ. ed.: Bandura A. Teoriya sotsial'nogo naucheniya. St. Petersburg, Evraziya Publ., 2000, pp. 13-28). 
6. Bernshtein S. B. Zigzagi pamyati. Vospominaniya. Dnevnikovye zapisi [Zigzags of memory. Memories. Diaries]. Moscow, 2002. 394 p.

7. Bekhterev V. M. Izbrannye trudy po psikhologii lichnosti. In 2 vol. [Selected works on personality psychology. In 2V.]. St. Petersburg, Aleteiya Publ., 1999, V. 1. 256 p.

8. Bratus' B. S. Studying the sense sphere of the person. Vestnik Moskovskogo un-ta. Ser. 14. Psikhologiya - Moscow University Psychology Bulletin, 1981, no. 2, pp. 46-56 (in Russian).

9. Brushlinskii A. V., Kol'tsova V. A. Socio-psychological concept of V. M. Bekhterev. In: Izbrannye raboty po sotsial'noi psikhologii [Selected works in social psychology]. Moscow, Nauka Publ., 1996, pp. 145-149.

10. Vygotskii L. S. Sobranie sochinenii [Collected works]. Moscow, 1983, V.3.641 p.

11. Gippenreiter Yu. B. Psikhologiya emotsii [Psychology of emotions]. Moscow, 1984. 336 p.

12. Grof K. Dukhovnyi krizis: Kogda preobrazovanie lichnosti stanovitsya krizisom [Spiritual crisis: When the transformation of personality becomes a crisis]. Moscow, 2003. 377 p.

13. Kara Zh. Yu., Kruteleva L. Yu. On the relationship of concepts: sense-life orientations, sense-life strategies, and sense-life concept of personality. Izvestiya Yuzhnogo federal'nogo universiteta. Pedagogicheskie nauki - News of Southern Federal University. Pedagogical sciences, 2012, V. 1, pp. 111-116 (in Russian).

14. Kozlov V. V., Kozlova A. A. Upravlenie konfliktom [Conflict management]. Moscow, EKSMO Publ., 2014. 224 p.

15. Collins R. The sociology of philosophies: A global theory of intellectual change. Harvard University Press, 1998. 1098 p. (Russ. ed.: Kollinz R. Sotsiologiya filosofii. Global'naya teoriya intellektual'nogo izmeneniya. Novosibirsk, Sibirskii khronograf Publ., 2002. 1282 p.).

16. Kretschmer E. Medical psychology. Moscow, Soyuz Publ., 1989. 464 p. (in Russian).

17. Lazurskii A. F. Klassifikatsiya lichnostei [Classification of personalities]. Leningrad, Gosizdat Publ., 1924. 290 p.

18. Levin K. Dynamic psychology: Selected works. Moscow, Smysl Publ., 2001. 572 p. (in Russian).

19. Levin K. Field theory in social science. St. Petersburg, Sensor Publ., 2000. 368 p. (in Russian).

20. Leont'ev A. N. Deyatel'nost'. Soznanie. Lichnost'[Activity. Consciousness. Personality]. Moscow, Politizdat Publ., 1975. 170 p.

21. Leont'ev D. A. Personality theory by A. F. Lazurskii: from propensity to relations. Metodologiya $i$ istoriya psikhologii - Methodology and History of Psychology, 2008, V. 3, no. 4, pp. 7-20 (in Russian). 
22. Lichko A. E. Psikhopatii i aktsentuatsiya kharaktera u podrostkov [Psychopathies and character accentuation in adolescents]. Leningrad, Meditsina Publ., 1983. 256 p.

23. Lomov B. F. Metodologicheskie i teoreticheskie problemy psikhologii [Methodological and theoretical problems of psychology]. Moscow, Nauka Publ., 1984. 445 p.

24. Magomed-Eminov M. Sh. Deyatel'nostno-smyslovoi podkhod kpsikhologicheskoi transformatsii lichnosti [Activity and sense approach to psychological transformation of personality]. Diss. Dr. Sci. (Psych.). Moscow, 2009. 680 p.

25. Muddy S. Personality theories: a comparative analysis. Homewood, ILL: Dorsey Press, 1968 (Russ. ed.: Maddi S. Teorii lichnosti: sravnitel'nyi analiz. St. Petersburg, Rech' Publ., 2002. 539 p.).

26. Merlin V. S. Psikhologiya individual'nosti [Psychology of individuality]. Voronezh: MODEK Publ., 1996. 448 p.

27. Allport G. Personality formation: Selected works. Moscow, Smysl Publ., 2002. 356 p. (in Russian).

28. Piaget J. The psychology of intelligence. London: Routledge and Kegan Paul, 1951 (Russ. ed.: Piazhe Zh. Psikhologiya intellekta. St. Petersburg, 2003).

29. Rimareva I. I. Transformation of the scientist's personality (the autobiographical excursus). Molodoi uchenyi - Young Scientist, 2014, no. 8, pp. 725-730 (in Russian).

30. Rogers C. R. Client-centered therapy. Boston: Houghton Mifflin, 1951 (Russ. ed.: Rodzhers K. R. Klient-tsentrirovannaya psikhoterapiya. Moscow, EKSMOPress Publ., 2002. 175 p.).

31. Rubinshtein S. L. Izbrannye filosofsko-psikhologicheskie trudy. Osnovy ontologii, logiki i psikhologii [Selected philosophical and psychological works. Fundamentals of ontology, logic, and psychology]. Moscow, Nauka Publ., 1997. 463 p.

32. Seryi A. V. Psikhologicheskie mekhanizmy funktsionirovaniya sistemy lichnostnykh smyslov [Psychological mechanisms of functioning of the system of personal senses]. Kemerovo, Kuzbassvuzizdat, 2002. 183 p.

33. Skinner B. Operant behavior. In: Istoriya zarubezhnoi psikhologii (30-60-e gg. XX v.). Teksty [History of foreign psychology (30-60-ies of 21 st century). Texts]. Moscow, 1986.

34. Uryvaev V. A., Boichuk B. V. Transformations of personality as a multidimensional problem. Klinicheskaya i meditsinskaya psikhologiya: issledovaniya, obuchenie, praktika - Clinical and Medical Psychology: Research, Training, and Practice, 2013, no. 2 (2). Available at: http://medpsy.ru/climp

35. FrankI V. Man's search for meaning: biographical sketch. Moscow, Progress Publ., 2010. 368 p. (in Russian). 
36. Freud S. Essays on the history of psychoanalysis. In: «Ya» $i$ «ONO» ("Ego" and "Id"). Tbilisi, 1991, V. 1. 274 p.

37. Hall C. S., Lindsey G. Theories of Personality. New York: John Wiley and Sons, 1970 (Russ. ed.: Kholl K., Lindsei G. Teorii lichnosti. Moscow, KSP+ Publ., 1997. 720 p.).

38. Horney K. The collected works of Karen Horney, New York:W. W. Norton Company, 1942. 230 p. (Russ. ed.: Khorni K. Sobranie sochinenii: V 3 t. Moscow, Smysl Publ., 1997. 342 p.).

39. Hjelle L., Ziegler D. Personality theories: Basic assumptions, research, and applications. 3th ed.: McGrow-Hill, 1992 (Russ. ed.: Kh'ell L., Zigler D. Teorii lichnosti. St. Petersburg, Piter Press Publ., 1997. 275 p.).

40. Jung C. G. Psychological types. St. Petersburg, Yuventa Publ., 1995. 717 p. (in Russian).

41. Jung C. G. Symbols of transformation. Moscow, Penta-Graphic Publ., 2000. 496 p. (in Russian).

42. Abakumova I., Kruteleva L., Ryadinskaya E. Transformation of Life-Sense Strategies of a Person in the Armed Conflict Environment: Theoretical Research. In: 6th.World Congress of Psychology and Behavioral Sciences (Management, Psychology, Political and Social Sciences) (WCPBS2016). Barselona, 2016, pp. 1-6.

43. Baumeister R., Leary M. The Need to Belong: Desire for Interpersonal Attachments as a Fundamental Human Motivation. Psychological Bulletin, 1995 , no. 117 , pp. 113-115.

44. Cattell R. B. The birth of the Society of Multivariate Experimental Psychology. Journal of the History of the Behavioral Sciences, 1990, 26 (1), pp. 48-57.

45. Dewey J. The quest for certainty. N. Y., Minton, Balch, 1929. 283 p.

46. Frankl V. E. The unheard cry for meaning: Psychotherapy and humanism. New York, NY, Simon \& Schuster, 2011. 184 p.

47. Heatherton T. F., Weinberger J. L. Can personality change? Washington (DC), American Psychological Association, 1994. 301 p.

48. Kelly G. A theory of personality: The psychology of personal constructs. New York, Norton, 1963, pp. 238-240.

49. Maslow Abraham H. Towards a Psychology of Being. Third edition. NY, John Wiley \& Sons, 1998, p. 89.

50. Ryadinskaya Yev. Theoretical analysis of a systematic approach to the study of the strategies of life meaning of the individual under an armed conflict. In: "The Tenth International Conference on Eurasian scientific development". Proceedings of the Conference (September 02, 2016). Vienna, 2016, pp. 40-43.

51. Sheldon B. Behavioral Approaches with Psychiatric Patients. In: Social Work and Mental Health. L., Tavistock Publications, 1984, pp. 243-324. 